\title{
ASSESSMENT OF CAROTID ATHEROSCLEROSIS IN RHEUMATOID ARTHRITIS IN ASIAN INDIAN COHORT: A CROSS-SECTIONAL STUDY
}

\author{
Santosh Kumar Mandal1, Partha Sarkar², R. N. Sarkar ${ }^{3}$, Nikhil Gupta4 \\ ${ }^{1}$ Consultant, Department of Clinical Immunology \& Rheumatology, CMC, Vellore. \\ ${ }^{2}$ Professor of Medicine, Department of Medicine, Calcutta National Medical College. \\ ${ }_{3}^{3}$ HOD, Department of Medicine, Calcutta Medical College. \\ ${ }^{4}$ Fellow, Department of Clinical Immunology \& Rheumatology, UCMS, CMC, Vellore
}

\begin{tabular}{l}
\hline ABSTRACT \\
BACKGROUND \\
Rheumatoid arthritis is a multisystem disease. Extra-articular manifestations add to morbidity and are the main cause of mortality \\
in Rheumatoid Arthritis. Cardiovascular disease in Rheumatoid arthritis is the main contributor to increase morbidity and mortality \\
in RA and is associated with premature atherosclerosis.
\end{tabular}

\section{AIM AND OBJECTIVE}

Study the incidence or occurrence of carotid atherosclerosis in Rheumatoid Arthritis and its correlation with inflammatory markers and activity of the disease in Asian Indian cohort.

\section{METHOD AND MATERIAL}

A total of 60 cases were enrolled in the study after obtaining informed written consent, of which 30 were RA patients fulfilling the ACR 1987 criteria for Rheumatoid arthritis and 30 were matched, healthy control. Measuring the Intima-Media Thickness (IMT) of the carotid artery bifurcation with ultrasonogram Doppler using a high resolution 7.5 - MHz linear transducer.

\section{RESULTS}

Mean age of patients with Rheumatoid arthritis was $42.69 \pm 14.89$ years, while that of controls was $41.17 \pm 12.01$ years (p -0.81 ). Carotid Intima-Media Thickness was significantly higher $(0.626 \pm 0.124$ Vs $0.455 \pm 0.057 ; \mathrm{P}<0.0001)$ in RA patients as compared to the control group.

\section{CONCLUSION}

Patients with rheumatoid arthritis have a marked increase in carotid atherosclerosis and carotid - IMT independent of traditional risk factors including age.

\section{KEYWORDS}

Rheumatoid Arthritis, CIMT, Carotid Plaque, Atherosclerosis.

HOW TO CITE THIS ARTICLE: Mandal SK, Sarkar P, Sarkar RN, et al. Assessment of carotid atherosclerosis in rheumatoid arthritis in Asian Indian cohort: a cross-sectional study. J. Evolution Med. Dent. Sci. 2016;5(65):4666-4672, DOI: 10.14260/jemds/2016/1063

\section{INTRODUCTION}

Rheumatoid Arthritis (RA) is a chronic inflammatory, multisystem disease. Cardiovascular diseases are the main contributor to increase morbidity and mortality in RA. Apart from the classical cardiac manifestation of RA including pericarditis, cardiomyopathy, myocarditis, cardiac amyloidosis, coronary vasculitis, arrhythmia and valve diseases, congestive heart failure, ischaemic heart disease and premature atherosclerosis are known to occur more frequently and are associated with an increased mortality compared with the general population. ${ }^{1}$ Traditional cardiovascular risk factors do not adequately account for the extent of cardiovascular disease in RA.2,3 Markers of inflammation are associated with ultrasonographically determined subclinical atherosclerosis, a predictor of

Financial or Other, Competing Interest: None.

Submission 07-07-2016, Peer Review 30-07-2016,

Acceptance 06-08-2016, Published 13-08-2016.

Corresponding Author:

Nikhil Gupta,

Fellow Clinical Immunology \& Rheumatology,

CMC, Vellore,

Department of Medicine, UCMS

Dilshad Garden, Delhi-110095.

E-mail: drnikhilguptamamc@gmail.com

DOI: $10.14260 / \mathrm{jemds} / 2016 / 1063$ cardiovascular events. ${ }^{3}$ The magnitude and chronicity of the inflammatory response, as measured by C-Reactive Protein, correlates with carotid atherosclerosis development in RA. ${ }^{3}$

An increased prevalence of subclinical atherosclerotic findings in long-term treated RA patients without clinical evidence of atherosclerotic disease has been reported. ${ }^{3}$ Patients with RA have impaired endothelial function and less favourable traditional cardiovascular risk factor profiles. Thus, both traditional and non-traditional cardiovascular risk factors appear to contribute to the dysfunctional endothelium in RA patients. ${ }^{4}$ In this study, we examined the occurrence of carotid atherosclerosis in patients with RA by using ultrasonogram - defined carotid artery plaque as a direct measure and proxy for generalised atherosclerosis and as a surrogate for coronary atherosclerosis 5 ; we also examined those features of RA that predict plaque presence. Preclinical disease was also to be identified by using ultrasonography to determine carotid intima-media thickness, an indirect measure of atherosclerosis. ${ }^{6}$

\section{AIMS AND OBJECTIVE}

Study the incidence or occurrence of carotid atherosclerosis in Rheumatoid Arthritis and its correlation with inflammatory markers and activity of the disease in Asian Indian cohort. 


\section{METHOD AND MATERIAL}

It was a Hospital-Based, Matched, Cross-Sectional Observational Study.

The study was carried out at Medical College and Hospital, Kolkata, from 1st May 2007 - 30th April 2008.

Patients attending Rheumatology and General Medicine Outdoor and Inpatient of Medicine Wards of Medical College and Hospital, Kolkata, were included in the study.

\section{Sample Design and Size}

Sample populations were divided into two groups:

Group I: Cases diagnosed as Rheumatoid Arthritis as per Revised ACR Criteria, 19877 were included.

\section{Inclusion Criteria}

- Age: $18-60$ years.

- Cases diagnosed as rheumatoid arthritis as per Revised ACR Criteria, 1987.7

1987 REVISED ACR CRITERIA FOR CLASSIFICATION OF
RA

\section{Guidelines for Classification}

1. Four of seven criterias are required to classify a patient as having RA.

2. Patients with two or more clinical diagnoses are not excluded.

\section{Criteria}

a. Morning Stiffness: Stiffness in and around the joints lasting 1 hour or more before maximal improvement.

b. Arthritis of three or more joint areas observed simultaneously. The 14 possible areas involved are right or left PIP, MCP, wrist, elbow and knee, ankle and MTP joints.

c. Arthritis of hand joints: Wrist, MCP or PIP joints.

d. Symmetric arthritis.

e. Rheumatoid Nodules: Subcutaneous nodules over bony prominences, extensor surfaces or juxta-articular.

\section{Regions}

Serum RF: Demonstration of abnormal amounts by any method for which the result has been positive in less than $5 \%$ of normal control subjects.

f. Radiographic Changes: Typical changes of RA on Posteroanterior hand and wrist radiographs that must include erosions or unequivocal bony decalcification localized in or most marked adjacent to the involved joints.

Criteria a-d must be present for at least 6 weeks.

Criteria b-e must be observed by a physician.

Group II - Included the Healthy controls.

\section{Exclusion Criteria Included}

a. Age $<18$ years.

b. Serum creatinine level $\geq 3.0 \mathrm{mg} / \mathrm{dL}$.

c. Blood Pressure (BP) $\geq 140 / 90 \mathrm{mmHg}$.

d. History of coronary artery disease.

e. Fasting blood sugar $\geq 126 \mathrm{mg} / \mathrm{dL}$ or Random blood sugar $\geq 200$ plus symptoms of diabetes.

f. Current or recent (within the past 3 months) pregnancy.

Thus, a total of 60 cases were enrolled in the study after obtaining informed written consent, of which 30 were RA patients (Group I) and 30 were matched, healthy control (Group II).
No guideline on therapy on the basis of outcome of the study was decided upon beforehand and thus was not included in computing the outcome of the study.

\section{Parameters to be Studied}

After obtaining written informed consent, the cases of both the groups were subjected to the following investigations:

a. Measuring the Intima-Media Thickness (IMT) of the carotid artery bifurcation with ultrasonogram Doppler using a high resolution 7.5 - MHz linear transducer. ${ }^{8}$

b. Thorough history was taken and clinical examination of both the groups was done. Both the groups were then subjected to blood, urine and radiological investigations.

c. Detection of carotid artery plaque with ultra-sonogram Doppler using a high resolution 7.5 MHz transducer. ${ }^{8}$

d. Disease activity score and Multi-Dimensional Health Assessment questionnaire for measurement of disease activity in all cases. ${ }^{9}$

\section{Disease Activity Score (DAS)}

It is a dynamic quantitative measure of rheumatoid inflammatory activity. It is an important instrument in assessing both disease severity and therapeutic response. ${ }^{10}$ The most popular version is the DAS-28. The 28 tender/swollen joint included bilateral wrists, MCP, PIP, elbow, shoulder and knee joints.

DAS-28 $=0.56 \times \sqrt{(\mathrm{t} 28)}+0.28 \times \sqrt{(\mathrm{sw} 28)}+0.70 \times \operatorname{Ln}(\mathrm{ESR})+$ $0.014 \times \mathrm{GH}$, where t28 is tender joints of 28 counted, sw28 is swollen joints of 28 counted; GH is general health status assessment by patient, $100 \mathrm{~mm}$ visual analog scale.

It was calculated using programmed calculator "Rheumatology Calculator LN-28," Pharmacal, China or URL:http://das-score.nl/www.das-score.nl/index.html

- High disease activity $>5.1$.

- Low disease activity $<3.2$.

- Remission $<2.6$.

\section{Health Assessment Questionnaire (HAQ). ${ }^{9}$}

The HAQ or modified HAQ (mHAQ) are patient self-reported functional questionnaire. It correlates significantly with disease activity. It also predicts work disability, functional status better than traditional measures of disease activity. Stanford University, USA was used in the study, downloaded from URL: http://aramis.stanford.edu/. The questions were slightly modified with respect to Indian lifestyle context. A score of 0 to 100 is obtained.

\section{Visual Analog Scale (VAS) for Pain (VAS-Pain)}

It assesses arthritis-related pain and its severity over the past week. It is measured on a double-anchored VAS (a horizontal line where each end represents opposite ends of a continuum) that is standardized to 15 centimetres in length. It is labelled $0=$ no pain at left anchor point and $100=$ severe pain at the right anchor point. Patients are instructed to place a vertical mark on the line to indicate the severity of their pain.

Visual Analog Scale for Global Health Assessment by Patient (VAS-GH Patient)

It is a validated measure of quality of life. It is a 15 -centimetre, double-anchored, horizontal VAS that starts at $0=$ very well to $100=$ very poor. 
Handling patient responses and scoring are similar to the pain scale.

Visual Analog Scale for Global Health Assessment by Physician (VAS-GH Physician)

It is similar to VAS-global health assessment by patient, except that response is given by the attending physician.

The detailed history, clinical examination and all investigational reports were recorded on the proforma maintained for the purpose.

\section{Carotid Ultrasonography}

All study participants underwent carotid ultrasonography, which was performed with ultrasonogram Doppler using high resolution 7.5 MHz transducer probe in hp-Agilent machine (Netherlands) by experienced sonographers in Department of Radiology, Medical College and Hospital, Kolkata.

Participants were studied in the supine position with slight hyperextension of the neck. Both extracranial carotid systems were extensively scanned in multiple planes to optimize identification of atherosclerosis, which was defined as discrete plaque protruding into the lumen at least $50 \%$ beyond the diameter of the surrounding wall. Doppler interrogation was performed to evaluate the presence of significant $(\geq 50 \%$ diameter reduction) obstruction. Intima-Media Thickness was measured from end-diastolic (minimum dimension) M-mode images of the far wall of the distal common carotid artery at the bifurcation. Intima-Media Thickness was not measured in a location containing plaque. Mean values of right and left Intima-Media Thickness are presented.

\section{Analysis of Data}

Data are expressed as mean \pm standard deviation for continuously distributed variables, and in absolute numbers and percentages for the discrete variables.
Tests of Significance

1. Chi-square test ( $\chi^{2}$, Pearson's) and Unpaired Student's ttest were used.

A P value of $<0.05$ was considered significant.

2. Pearson's product moment correlation coefficient was used for correlation.

\section{RESULT AND ANALYSIS}

\begin{tabular}{|c|c|c|c|}
\hline & $\begin{array}{c}\text { RA } \\
(\mathbf{n = 3 0 )}\end{array}$ & $\begin{array}{c}\text { Controls } \\
(\mathbf{n = 3 0 )}\end{array}$ & P value \\
\hline Age & $42.69 \pm 14.89$ & $41.17 \pm 12.01$ & 0.81 \\
\hline Male Gender & $6(20 \%)$ & $8(26.67 \%)$ & $0.542 \#$ \\
\hline $\begin{array}{c}\text { Body Mass } \\
\text { Index }\end{array}$ & $23.66 \pm 3.29$ & $22.78 \pm 2.63$ & 0.26 \\
\hline $\begin{array}{c}\text { Cigarette } \\
\text { Smoker }\end{array}$ & $4(13.33 \%)$ & $5(16.67 \%)$ & $0.718 \#$ \\
\hline $\begin{array}{c}\text { OCP Use in } \\
\text { Female }\end{array}$ & $3(12.5 \%)$ & $4(17.40 \%)$ & $0.592 \#$ \\
\hline Menopause & $7(29.17 \%)$ & $2(8.7 \%)$ & $0.0745 \#$ \\
\hline Systolic BP & $126.80 \pm 11.35$ & $128.53 \pm 9.02$ & 0.52 \\
\hline Diastolic BP & $79.20 \pm 12.10$ & $75.4 \pm 8.31$ & 0.16 \\
\hline \multicolumn{4}{|c|}{ Table 1: Demographic Profile of } \\
RA Patients and Controls \\
\hline \multicolumn{4}{|c|}{} \\
\hline
\end{tabular}

\section{\# Chi-Square test.}

Among the RA patients, all were positive for RF with mean titre of $148.94 \pm 225.72$. Out of 30 RA patients included in the study, $3(10 \%)$ were also suffering from hypothyroidism with normal TSH levels on therapy. Only $7(23.33 \%)$ patients and 3 $(10 \%)$ controls had positive family history of RA.

\begin{tabular}{|c|c|c|c|}
\hline & RA (n=30) & Controls (n=30) & P value \\
\hline Haemoglobin (gm/dL)* $^{*}$ & $11.10 \pm 1.64$ & $12.32 \pm 1.63$ & $0.01^{*}$ \\
\hline Platelet (cu.mm)* $^{*}$ & $383333.33 \pm 36301.74$ & $311833.33 \pm 36721$ & $<0.0001^{*}$ \\
\hline ESR (mm 1 ${ }^{\text {st }}$ Hour) & $64.23 \pm 32.35$ & $16.33 \pm 4.74$ & $<0.0001^{*}$ \\
\hline Triglyceride (mg/dL) & $132.87 \pm 25.34$ & $137.17 \pm 8.91$ & 0.384 \\
\hline Total Cholesterol (mg/dL) & $156 \pm 16.51$ & $155.17 \pm 11.27$ & 0.703 \\
\hline HDL - Cholesterol (mg/dL) & $39.63 \pm 5.41$ & $41 \pm 2.95$ & 0.229 \\
\hline LDL - Cholesterol (mg/dL) & $90.50 \pm 18.29$ & $86.80 \pm 10.82$ & 0.344 \\
\hline VLDL - Cholesterol (mg/dL) & $26.53 \pm 5.07$ & $27.43 \pm 2.01$ & 0.369 \\
\hline CC - IMT (mm)* & $0.629 \pm 0.124$ & $0.455 \pm 0.057$ & $<0.0001^{*}$ \\
\hline CAROTID PLAQUE* & $4(13.33 \%)$ & $0.0384^{*} \#$ \\
\hline Table 2: Laboratory Profile including CIMT and Presence of Carotid Plaque \\
\hline
\end{tabular}

*Significant $(\mathrm{P}<0.05)$, \#Calculated using Chi Square test. Even though both groups had similar lipid parameter distribution, the common Carotid-Intima Media Thickness (CIMT) was significantly higher $(0.626 \pm 0.124$ Vs $0.455 \pm 0.057$; $\mathrm{P}<0.0001)$ in RA patients compared to the control group.

\begin{tabular}{|c|c|c|c|}
\hline & $\begin{array}{c}\text { Without Plaque } \\
(\mathbf{N = 2 6 )}\end{array}$ & $\begin{array}{c}\text { With Plaques } \\
\mathbf{( N = 0 4 )}\end{array}$ & P value \\
\hline Age, years & $40.08 \pm 14.7$ & $54.5 \pm 10.15$ & 0.054 \\
\hline BMI & $23.64 \pm 3.35$ & $23.78 \pm 3.4$ & 0.948 \\
\hline $\begin{array}{c}\text { SBP } \geq 120 \\
\mathrm{mmHg}\end{array}$ & $126.54 \pm 10.74$ & $128.5 \pm 16.68$ & 0.754 \\
\hline $\begin{array}{c}\mathrm{DBP} \geq 80 \\
\mathrm{mmHg}\end{array}$ & $78.38 \pm 12.58$ & $84.5 \pm 7.19$ & 0.36 \\
\hline
\end{tabular}

\begin{tabular}{|c|c|c|c|}
\hline $\begin{array}{c}\text { Disease } \\
\text { Duration, } \\
\text { Years }\end{array}$ & $4.88 \pm 4.82$ & $6.25 \pm 5.32$ & 0.604 \\
\hline Smoker & $2(7.7 \%)$ & $2(50 \%)$ & $0.0204^{*} \#$ \\
\hline Family History & $6(23 \%)$ & $1(25 \%)$ & $0.934 \#$ \\
\hline Male (n=6) & $3(50 \%)$ & $3(50 \%)$ & $0.0031^{*} \#$ \\
\hline $\begin{array}{c}\text { Menopause } \\
\text { (n=7) }\end{array}$ & $6(85.7 \%)$ & $1(14.3 \%)$ & $0.1114 \#$ \\
\hline
\end{tabular}

Table 3: Clinical Parameters in RA Patients With or Without Plaque

*Significant $(\mathrm{P}<0.05)$, \#Calculated using Chi Square test. 


\begin{tabular}{|c|c|c|c|}
\hline & Without Plaque (N=26) & With Plaques (N=04) & P value \\
\hline Haemoglobin, gm/dL & $10.95 \pm 1.54$ & $12.10 \pm 2.19$ & 0.197 \\
\hline Platelet count, cu.mm & $379615.38 \pm 37119.35$ & $407500 \pm 18929.09$ & 0.156 \\
\hline Total Cholesterol & $155.62 \pm 16.68$ & $162.75 \pm 16.05$ & 0.431 \\
\hline HDL-C & $40.31 \pm 5.39$ & $35.25 \pm 3.4$ & 0.0814 \\
\hline LDL-C & $89.73 \pm 18.15$ & $95.5 \pm 21.21$ & 0.566 \\
\hline VLDL-C & $25.69 \pm 4.04$ & $32 \pm 8.10$ & $0.017^{*}$ \\
\hline Triglyceride & $128.62 \pm 20.22$ & $160.50 \pm 40.34$ & $0.016^{*}$ \\
\hline ESR & $63.08 \pm 31.83$ & $71.75 \pm 39.84$ & 0.282 \\
\hline CRP & $36.35 \pm 18.28$ & $41.8 \pm 23.32$ & 0.28 \\
\hline Erosions & $5(19.23 \%)$ & $3(75 \%)$ & $0.0188^{*} \#$ \\
\hline CC-IMT & $0.604 \pm .108$ & $0.79 \pm 0.11$ & $0.0044^{*}$ \\
\hline DAS-28 & $5.53 \pm 0.9$ & $6.10 \pm 1.46$ & 0.282 \\
\hline HAQ & $10.85 \pm 7.64$ & $15.31 \pm 7.17$ & 0.283 \\
\hline Table 4: Laboratory Parameters and Disease Activity Markers in RA Patients With or Without Plaque
\end{tabular}

*Significant $\mathrm{P}<0.05$, \# Chi-Square test.

\begin{tabular}{|c|c|c|}
\hline & $\begin{array}{c}\text { Pearson's Univariate Correlation } \\
\text { Coefficient in RA }\end{array}$ & $\begin{array}{c}\text { Pearson's Univariate Correlation } \\
\text { Coefficient in Control Sample }\end{array}$ \\
\hline Age & 0.4035 & 0.311 \\
\hline BMI & 0.137 & 0.345 \\
\hline Cigarette Smoker & 0.613 & 0.30 \\
\hline Male Gender & 0.241 & 0.334 \\
\hline SBP & 0.1616 & 0.229 \\
\hline DBP & 0.1802 & 0.292 \\
\hline Disease Duration & 0.315 & 0.01 \\
\hline Platelet Count & 0.23 & 0.01 \\
\hline ESR & 0.12 & 0.01 \\
\hline CRP & 0.112 & 0.285 \\
\hline Total Cholesterol & 0.1619 & 0.406 \\
\hline Triglyceride & 0.3677 & -0.28 \\
\hline HDL - Cholesterol & -0.3154 & 0.293 \\
\hline LDL - Cholesterol & 0.1392 & 0.45 \\
\hline VLDL - Cholesterol & 0.3646 & \\
\hline DAS - 28 Score & 0.1370 & \\
\hline HAQ Score & 0.0862 & \\
\hline \multicolumn{2}{|c|}{ Table 5: Pearson's Univariate Correlation Coefficient of Various Factors Affecting CC-IMT } \\
\hline
\end{tabular}

Strength of correlation $>0.8=$ strong, $<0.3=$ weak.

\begin{tabular}{|c|c|c|}
\hline & $\begin{array}{c}\text { Pearson's Univariate Correlation } \\
\text { Coefficient of DAS-28 Score }\end{array}$ & $\begin{array}{c}\text { Pearson's Univariate Correlation } \\
\text { Coefficient of HAQ - Score }\end{array}$ \\
\hline AGE & 0.205 & 0.384 \\
\hline BMI & 0.068 & 0.052 \\
\hline SBP & 0.5 & 0.45 \\
\hline DBP & 0.148 & 0.294 \\
\hline Disease Duration & 0.287 & 0.262 \\
\hline RF Titre & 0.13 & 0.289 \\
\hline Haemoglobin, gm/dL & -0.477 & -0.36 \\
\hline Platelet Count & 0.16 & 0.13 \\
\hline ESR & 0.738 & 0.44 \\
\hline CRP & 0.73 & 0.45 \\
\hline Total Cholesterol & 0.278 & 0.167 \\
\hline HDL-Cholesterol & 0.024 & -0.045 \\
\hline LDL-Cholesterol & 0.273 & 0.093 \\
\hline VLDL-Cholesterol & 0.1307 & 0.243 \\
\hline
\end{tabular}




\begin{tabular}{|c|c|c|}
\hline Triglyceride & 0.127 & 0.245 \\
\hline CC-IMT & 0.14 & 0.09 \\
\hline DAS-28/HAQ & 0.68 & 0.68 \\
\hline \multicolumn{2}{|c|}{ Table 6: Pearson's Univariate Correlation Coefficient of Various Factors Affecting Disease Activity in RA Patients } \\
\hline
\end{tabular}

\begin{tabular}{|c|c|c|c|c|c|}
\hline & Total Cholesterol & HDL-Cholesterol & LDL-Cholesterol & VLDL-Cholesterol & Triglyceride \\
\hline AGE & 0.401 & 0.01 & 0.334 & 0.14 & 0.139 \\
\hline BMI & 0.21 & 0.13 & 0.24 & 0.06 & 0.06 \\
\hline SBP & 0.58 & -0.05 & 0.525 & 0.06 & 0.067 \\
\hline DBP & 0.312 & 0.01 & 0.254 & 0.10 & 0.11 \\
\hline Disease Duration & 0.28 & 0.20 & 0.153 & 0.132 & 0.14 \\
\hline RF Titre & 0.001 & 0.19 & 0.10 & 0.18 & 0.20 \\
\hline Platelet Count & 0.17 & 0.16 & 0.10 & 0.03 & 0.03 \\
\hline ESR & 0.32 & -0.03 & 0.34 & 0.18 & 0.17 \\
\hline CRP & 0.31 & 0.02 & 0.332 & 0.18 & 0.17 \\
\hline CC-IMT & 0.162 & -0.32 & 0.139 & 0.365 & 0.367 \\
\hline DAS-28 score & 0.278 & 0.024 & 0.273 & 0.131 & 0.127 \\
\hline HAQ score & 0.167 & -0.045 & 0.093 & 0.243 & 0.245 \\
\hline \multicolumn{2}{|l|}{ Table 7: Pearson's Univariate Correlation Coefficient of Various Factors Affecting Lipid Profile in RA Patients } \\
\hline
\end{tabular}

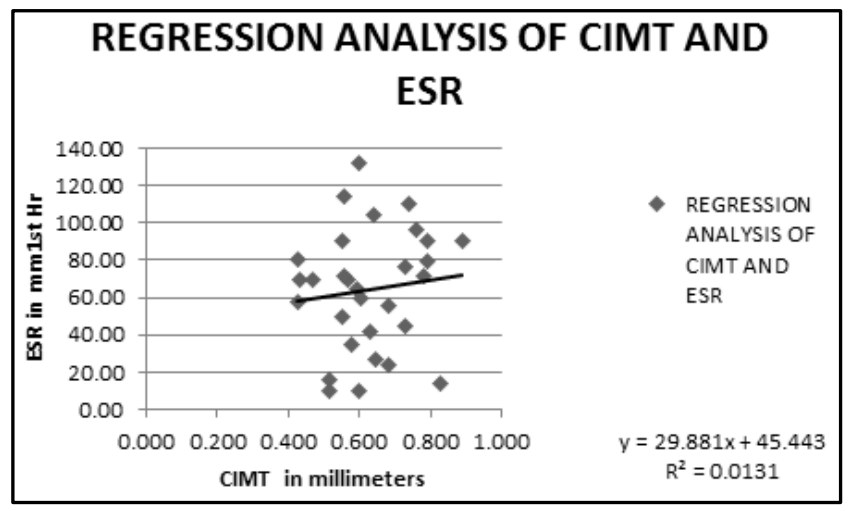

Fig. 1: Shows Linear Regression Analysis between CIMT and the Level of ESR in RA with an Upsloping Trendline, but the Variables are Diffusely Scattered around the Trendline Suggesting a Weak Correlation between the CIMT and ESR Value

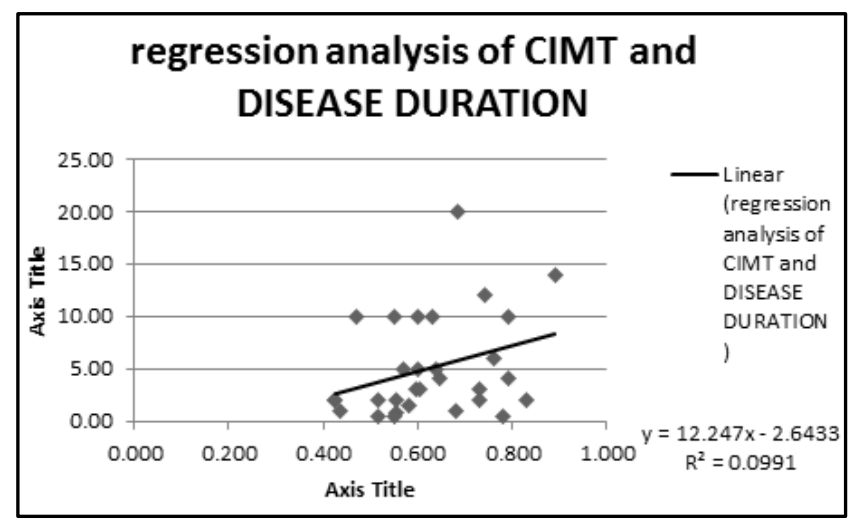

Fig. 2: Shows the Correlation of CIMT with Duration of RA with Upsloping Trendline and Most of the Variables is Around the Trendline and a few Away from the Trendline, suggesting a Moderately Strong Positive Correlation between them

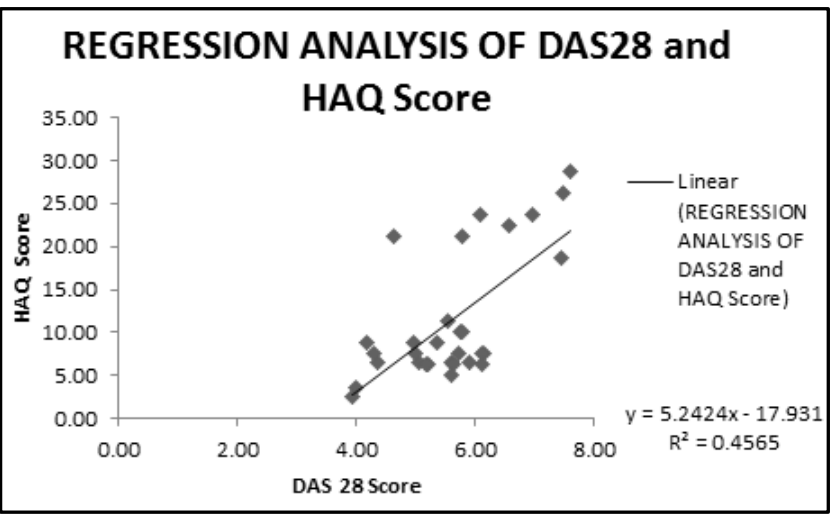

Fig. 3: Shows the Linear Regression Analysis of the Two Disease Activity Scores, Commonly Used to Assess the Disease Activity in RA. There is Upsloping Trendline with nearly all Variables Close to the Trendline, Suggesting a Fairly Strong Positive Correlation between the Two Disease Activity Scores

\section{DISCUSSION}

Our study documents an increased occurrence of carotid atherosclerosis (3-4 folds higher) in patients with RA compared to age, sex and BMI matched healthy controls. The increased risk occurred despite both the groups having similar systolic blood pressure, diastolic blood pressure and lipid parameters. Roman JM et al,11 Gonzalez-Juanatey C et al,12 Jonsson SW et al,13 Del Rincon ID et al ${ }^{14}$ and Rodriguez G et al ${ }^{15}$ to name a few studies in RA patients, documented a similar 3fold higher prevalence of carotid atherosclerosis in a matched, case control study, even with more adverse traditional atherosclerotic risk factors in the control group suggesting that probably chronic inflammation is the culprit. Similar increased prevalence of carotid atherosclerosis was shown by Mahajan $\mathrm{V}$ et $\mathrm{al}^{16}$ and Grover $\mathrm{S}$ et $\mathrm{al}^{17}$ in their recent study on Indian population.

Prevalence of carotid atherosclerosis in RA patients is increased with age and with a longer duration of disease. ${ }^{18}$ The mean age group of our patients with carotid atherosclerosis was 54.5 years compared to 40 years in patients without carotid atherosclerosis. In contrast to previous studies, the 
mean duration of disease of our patients is 6.25 years, suggesting an earlier onset. Jonsson SW et al ${ }^{13}$ in their study on atherosclerotic disease in recent onset RA, documented higher occurrence of carotid atherosclerosis in recent onset RA and suggested that inflammation, which precedes the onset of joint symptoms in RA promotes the development of atherosclerotic disease well before the first manifestation of joint disease. Similar data was shown in Nurses' Health Study.

In our study, though male formed only $20 \%$ of RA patients, about $50 \%$ had carotid atherosclerosis. Mahajan $\mathrm{V}$ et al ${ }^{16}$ in their study found that 35\% of male RA patients had carotid atherosclerosis. Male sex is considered a traditional risk factor for atherosclerosis.

Carotid atherosclerosis is more common in RA patients who were current smokers. In our study, 3/4th of patients with carotid atherosclerosis were smokers. Smoking is clearly a risk factor for RA development. Smoking exacerbates RA severity and is a risk factor for CIMT, carotid atherosclerosis and $\mathrm{CV}$ outcome in both RA patients and non-RA patients. ${ }^{19}$

Both inflammatory markers, ESR and CRP was higher in RA patients with carotid atherosclerosis, but were not statistically significant. This may be explained by use of conventional CRP assay, since involvement of CRP in atherosclerosis has been demonstrated by hs-CRP assay. ${ }^{20}$ Alternatively, serum CRP level determined by conventional assay often fluctuates in patients with chronic inflammatory diseases and since the atherosclerosis may be dependent on median of serial measurement of CRP levels, measurement of CRP at single point failed to be associated with carotid atherosclerosis.

Increased disease activity as measured by disease activity scores (DAS-28, HAQ), suggests ongoing chronic inflammation and may lead to dyslipidaemia. ${ }^{10}$ In our study, both the DAS28 and HAQ scores were higher in patients with carotid atherosclerosis and showed positive association. Hannawi $\mathrm{S}$ et $\mathrm{al}^{21}$ and others. ${ }^{13,15}$ showed similar positive association of carotid atherosclerosis and disease activity scores.

In RA patients with carotid atherosclerosis, there was increased occurrence of erosions on X-ray of hand joints and affected joints, which was statistically significant. Mahajan $V$ et al ${ }^{16}$ similarly showed in their study that presence of erosions on hand radiographs were significantly associated with the presence of carotid atherosclerosis. Validated scoring system ${ }^{22}$ such as Larsen's or sharp, based on conventional Xray are the gold standard for evaluation of RA progression, based on semi-quantitative measurement of radiographically visible disease - related alteration in particular erosion and joint space reduction. These were not in use in our study.

Mean common carotid artery Intima-Media Thickness (IMT) was significantly higher in RA patients with carotid atherosclerosis in our study, a finding substantiated by many studies.11-15 Even though the lipid parameters and other traditional risk factors for atherosclerosis were similar in both RA patients and control population, RA patients had a significantly higher mean common carotid artery IMT, suggesting a possible role of chronic inflammation. Common carotid artery IMT had good positive correlation with age in both RA patients and control population in our study. This finding is similar to that obtained by Indian16,17 and international studies. ${ }^{11-15}$

Higher carotid - IMT is positively correlated with duration of the disease and smoking in RA.11-15 We found good correlation of carotid - IMT with disease duration and cigarette smoking in pack-years. Smoking is a risk factor for CIMT and cardiovascular outcome in RA and non-RA patients. ${ }^{23,24}$

Contrary to other studies, ${ }^{11-15}$ weak positive correlation was obtained between CIMT and ESR, and CRP levels in our study as also in a similar study by Kumeda Y et al. ${ }^{6}$

The usual pattern of lipid abnormalities described in RA comprises low Total Cholesterol (TC), low High-Density Lipoprotein Cholesterol (HDL-C) and elevated Triglycerides (TG). ${ }^{25}$ Patients with active disease are known to have global reduction of all lipid subsets. Serum lipids are strong predictors of CVD risk, but in our study we found no significant difference in the lipid profile between the groups. This finding is in line with other studies. ${ }^{11}$ Furthermore, reduction in disease activity tends to normalize lipid parameters. Lipid abnormalities are very common in Indian RA patients with low HDL-cholesterol being commonest dyslipidaemia encountered. ${ }^{26}$ But in our study, RA patients with carotid atherosclerosis had higher mean total cholesterol and LDLcholesterol and lower mean HDL-cholesterol, and we obtained good positive correlation between CIMT and triglyceride, and VLDL-cholesterol levels; and good negative correlation between CIMT and HDL-cholesterol levels. This may be explained by the studies in Asian Indians, which suggested that Asian Indians are metabolically disadvantaged population with higher prevalence of obesity, diabetes mellitus and dyslipidaemia. ${ }^{27}$ Alternatively, serial measurements will be a better representative of effect of lipid abnormality on CIMT and carotid atherosclerosis. The effects of antirheumatic drugs should also be taken into account as certain second-line agents may lead to normalisation of the lipid profile. ${ }^{28}$ Furthermore, in a disease like RA characterized by disturbed antioxidant mechanisms (Oxidative stress), a high proportion of LowDensity Lipoprotein (LDL) is oxidized, even at a lower ambient lipid concentration, thus placing RA patients at an even higher cardiovascular risk. ${ }^{29}$

In contrast to other studies. ${ }^{6}$ disease activity scores (DAS8 and HAQ), showed weak positive correlation with CIMT in RA patients in our study. But we found good positive correlation with ESR, CRP, and systolic blood pressure and weak correlation with lipid parameters. The relation of DAS28 and HAQ with ESR, CRP and Systolic BP has been substantiated in many studies. 10 but inconsistent association has been seen with lipid parameters.

Thus, we found in our study, that there is higher occurrence of carotid atherosclerosis and common carotid artery - IMT compared to age, sex and BMI matched control population. Even though the difference in mean systolic BP and dyslipidaemia were insignificant between both the groups, RA patients had higher occurrence of carotid atherosclerosis and carotid artery - IMT. Within the RA group, carotid atherosclerosis was more in patients with advanced age, longer duration of disease, higher disease activity and presence of erosions on X-rays.

\section{CONCLUSION}

Patients with rheumatoid arthritis have a marked increase in carotid atherosclerosis and carotid-IMT independent of traditional risk factors including age.

Higher carotid-IMT is associated with duration of the disease, and is higher even in recent onset RA. Physicians 
caring for RA patients need to be aware of this important early extra-articular complication.

Carotid ultrasonography is a simple and inexpensive way of identifying preclinical atherosclerosis in this highly vulnerable population. Cost-effectiveness of this screening strategy needs to be ascertained in larger longitudinal studies.

In addition to prospective management of traditional cardiac risk factors, we emphasize the need for aggressive control of rheumatoid arthritis disease activity because chronic inflammation is probably a driving force for premature atherosclerosis.

Future research efforts should seek to define more precisely the mechanisms, whereby atherosclerosis is accelerated in persons with rheumatoid arthritis and to identify interventional strategies that will slow the development of clinical cardiovascular disease in this group.

\section{REFERENCES}

1. Voskusyl AE. The heart and cardiovascular manifestations in rheumatoid arthritis. Rheumatology (Oxford) 2006;45(Suppl4):iv4-7.

2. Del Rincon ID, Williams K, Stern MP, et al. High incidence of cardiovascular events in a rheumatoid arthritis cohort not explained by traditional cardiac risk factors. Arthritis Rheum 2001;44(12):2737-45.

3. Kaplan MJ. Cardiovascular diseases in rheumatoid arthritis. Curr Opin Rheumatology 2006;18(3):289-97.

4. Del Rincon ID, Freeman GL, Haas WR, et al. Relative contribution of cardiovascular risk factors and rheumatoid arthritis clinical manifestation to atherosclerosis. Arthritis Rheum 2005;52(11):3413-23.

5. Park YB, Ahn CW, Choi HK, et al. Atherosclerosis in rheumatoid arthritis: morphological evidence detected by ultrasonography in patients with rheumatoid arthritis. Arthritis Rheum 2002;46(7):1714-9.

6. Arnett FC, Edworthy SM, Bloch DA, et al. The American Rheumatism Association 1987 revised criteria for classification of rheumatoid arthritis. Arthritis Rheum 1988;31(3):315-24.

7. Roman MJ, Naqvi TZ, Gardin JM, et al. Clinical application of non-invasive vascular ultrasound in cardiovascular risk stratification: a report from American Society of Echocardiography and The Society for Vascular Medicine and Biology. Vasc Med 2006;11(3):201-11.

8. Pincus T, Swearingen C, Wolfe F. Towards a multidimensional health assessment questionnaire (MDHAQ): assessment of advanced activities of daily living and psychological status in the patient-friendly health assessment questionnaire format. Arthritis Rheum 1999;42(10):2220-30.

9. Yildirim K, Karatay S, Melikoglu MA, et al. Associations between acute phase reactant levels and disease activity score (DAS-28) in patients with rheumatoid arthritis. Ann Clin Lab Sci 2004;34(4):423-6.

10. Roman JM, Moeller E, Davis A, et al. Preclinical carotid atherosclerosis in patients with rheumatoid arthritis. Ann Of Int Med 2006;144(4):249-56.

11. Gonzalez-Juanatey C, Llorca J, Testa A, et al. Increased prevalence of severe subclinical atherosclerotic findings in long-term treated rheumatoid arthritis patients without clinically evident atherosclerotic disease. Medicine (Baltimore) 2003;82(6):407-13.
12. Jonsson SW, Backman $\mathrm{C}$, Johnson $\mathrm{O}$, et al. Increased prevalence of atherosclerosis in patients with medium term rheumatoid arthritis. J Rheumatol 2001;28(12):2597-602.

13. Del Rincon ID, O'Leary DH, Freeman GLA, et al. Acceleration of atherosclerosis during the course of rheumatoid arthritis. J Atherosclerosis 2007;195(2):35460.

14. Rodriguez G, Sulli A, Cutolo M, et al. Carotid atherosclerosis in patients with rheumatoid arthritis: a preliminary casecontrol study. Ann NY Acad Sci 2002;966:478-82.

15. Mahajan V, Handa R, Kumar U, et al. Assessment of atherosclerosis by carotid intima-medial thickness in patients with rheumatoid arthritis. J Ass Phy India 2008;56:587-90.

16. Grover S, Sinha RP, Singh U, et al. Subclinical atherosclerosis in rheumatoid arthritis. Ind J Rheumatol 2006;33(2):244-7.

17. Stockman A, Tait BD, Wolfe R, et al. Clinical, laboratory and genetic markers associated with erosions and remission in patients with early rheumatoid arthritis: a prospective cohort study. Rheumatol Int 2006;26(6):500-9.

18. Solomon DH, Goodson NJ, Katz JN, et al. Patterns of cardiovascular risk in rheumatoid arthritis. Ann Rheum Dis 2006;65(12):1608-12.

19. Ridker PM. High sensitivity C-reactive protein: potential adjunct for global risk assessment in the primary prevention of cardiovascular disease. Circulation 2001;103(13):1813-8.

20. Hannawi S, Haluska B, Marwick TH, et al. Atherosclerotic disease is increased in recent-onset rheumatoid arthritis: a critical role for inflammation. Arthritis Res Ther 2007;9(6):R116.

21. Sambrook PN. The skeleton in rheumatoid arthritis: common mechanism for bone erosion and osteoporosis? J Rheumatol 2000;27(11):2541-2.

22. Wolfe F. The effect of smoking on clinical, laboratory, and radiographic status in rheumatoid arthritis. J Rheumatol 2000;27(3):630-7.

23. Harrison BJ. Influence of cigarette smoking on disease outcome in rheumatoid arthritis. Curr Opin Rheumatol 2002;14(2):93-7.

24. Situnayake RD, Kitas G. Dyslipidaemia and rheumatoid arthritis. Ann Rheum Dis 1997;56(6):341-2.

25. Vottery R, Saigal R, Singhal N, et al. Lipids profile and its relation to disease activity. J Assoc Physician India 2001;49:1188-90.

26. Misra A, Pandey RM, Devi JR, et al. High prevalence of diabetes, obesity and dyslipidaemias in urban slum population in Northern India. Int J Obes Relat Metab Disord 2001;25(11):1722-9.

27. Georgiadis AN, Papavasiliou EC, Lourida ES, et al. Atherogenic lipid profile is a feature characteristic of patients with early rheumatoid arthritis: effect of early treatment-a prospective, controlled study. Arthritis Res Ther 2006;8(3):R82.

28. Winyard PF, Tatzber F, Esterbauer H, et al. Presence of foam cells containing oxidized low density lipoprotein in the synovial membrane from patients with rheumatoid arthritis. Ann Rheum Dis 1993;52(9):677-80. 